\title{
Gerard Poulouin, Remy de Gourmont: de l'Ymagier à la Collection des plus belles pages
}

\section{Marco Garrone}

\section{(2) OpenEdition}

1 Journals

\section{Edizione digitale}

URL: https://journals.openedition.org/studifrancesi/38126

DOI: 10.4000/studifrancesi.38126

ISSN: 2421-5856

\section{Editore}

Rosenberg \& Sellier

\section{Edizione cartacea}

Data di pubblicazione: 15 décembre 2004

Paginazione: 640

ISSN: 0039-2944

\section{Notizia bibliografica digitale}

Marco Garrone, «Gerard Poulouin, Remy de Gourmont: de I'Ymagier à la Collection des plus belles pages», Studi Francesi [Online], 144 (XLVIII | III) | 2004, online dal 30 novembre 2015, consultato il 08 mai 2021 URL: http://journals.openedition.org/studifrancesi/38126 ; DOI: https://doi.org/10.4000/studifrancesi. 38126

Questo documento è stato generato automaticamente il 8 mai 2021.

\section{(c) $(1) \ominus$}

Studi Francesi è distribuita con Licenza Creative Commons Attribuzione - Non commerciale - Non opere derivate 4.0 Internazionale. 


\title{
Gerard Poulouin, Remy de Gourmont: de l'Ymagier à la Collection des plus belles pages
}

\author{
Marco Garrone
}

\section{NOTIZIA}

GERARD POULOUIN, Remy de Gourmont: de l'Ymagier à la Collection des plus belles pages, «Travaux de Littérature», XV, 2000, pp. 177-195.

1 Remy de Gourmont era discendente di alcuni dei più importanti tipografi e librai del XV e XVI secolo, tra cui Gilles de Gourmont, a cui si devono le prime stampe parigine fatte in caratteri greci ed ebraici. Al pari dei suoi antenati, lo stesso Remy si appassionò alla creazione tipografica dei libri, operando per molti anni come "autore-editore" e curando in particolare la rivista "L'Ymagier», che promosse sulle pagine del «Mercure de France» come rivista di immagini, e studi sulle immagini e sui creatori delle stesse, vecchi e nuovi. A questo progetto collaborò Alfred Jarry, che abbandonò però la rivista dopo il sesto numero. L'avventura editoriale rappresentata dall'Ymagier, si alternò con altre importanti iniziative; forte, infatti, fu l'interesse di G. per il Medioevo e per la spiritualità che segnò questo periodo (da ricordare ad esempio le edizioni rivisitate, corrette ed introdotte, di Le Miracle de Théophile di Rutebeuf, di Aucassin et Nicolette, etc.). La sua attività d'editore-scrittore privilegiò le tirature a carattere bibliofilo, nello spirito delle piccole riviste simboliste che si rivolgevano esclusivamente ad un limitato gruppo di letterati e cultori d'arte. Familiare della Biblioteca nazionale, e delle più vecchie librerie di Parigi, spesso riuscì anche a scovare manoscritti o testi antichi d'indubbio valore critico. Combinando il valore artistico di questi testi con il valore di alcuni artisti simbolisti che conosceva personalmente, G. diede vita ad opere di grande valore. In seguito ad una serie d'avvenimenti, tuttavia, G. si allontanò dall'ambiente simbolista, smettendo di stampare quelle plaquettes che facevano la felicità dei bibliofili come lui, per dedicarsi invece alla Collection des plus belles pages, ossia al recupero di un 
autore trascurato dalla critica. I primi autori trattati dalla Collection (cui collaborò anche Léautaud), furono Rétif de la Bretonne, Gerard de Nerval, e Chamfort. Nel 1906 G. si occupò invece della rivalutazione di Rivarol, di Henri Heine, di Tallemant des Réaux, Théophile de Viau e Saint-Amant. Tra le personalità analizzate dal G. da ricordare in particolar modo Stendhal, il cui lavoro di critica richiese ben tre anni: uno studio tuttavia così accurato che porta $\mathrm{G}$. ad essere considerato ancora oggi, a fianco di Adolphe Paupe, uno dei migliori specialisti di Stendhal. Anche se Gide trovò delle incompletezze nella bibliografia di Saint-Evremond, è essenziale sottolineare come il fine ultimo di G. non fosse la completezza di dati bio- e bibliografici: quello che G. realmente intendeva fare era riscoprire e far rivalutare alcuni di quei grandi geni letterari e spiriti liberi del passato a cui del resto lui si sentiva particolarmente affine. In una decina d'anni la Collection accolse e studiò una ventina d'autori. Tutti i volumi sono caratterizzati da una stessa tecnica compositiva: in apertura, di solito, un ritratto dell'autore, poi un'introduzione più o meno lunga che presenta l'uomo e lo scrittore con una cernita delle opere più rappresentative dello stesso, ed infine appendici dai contenuti variabili.

2 L'A., nella sua conclusione, vuole comunque precisare che il décalage tra l'attività di critico letterario e quella iniziale di scrittore-editore non fu mai così profondo: in entrambi, infatti, emerse un'immensa costanza nel lavoro e una grande curiosità intellettuale che lo accompagnava sempre, sia durante le ricerche serali di testi rari presso i bouquinistes, sia durante la stesura di note critiche su autori che ingiustamente rischiavano di essere dimenticati. 